\title{
Perfil de puérperas com intercorrências mamárias em uma maternidade Amiga da Criança
}

\author{
Profile of recently given birth with breast complications in child-friendly maternity hospital \\ Perfil de las puérperas con complicaciones mamarias en un hospital maternal amigo de \\ los niños
}

Ana Flávia Vaz de Abreu ${ }^{1 *}$, Flávia Pimentel Miranda ${ }^{2,3}$, Milla Calasans de Andrade².

\begin{abstract}
RESUMO
Objetivo: Descrever o perfil sociodemográfico, reprodutivo e obstétrico das mulheres com intercorrências mamárias relacionadas à amamentação em uma maternidade de Salvador-Bahia (BA). Métodos: Estudo exploratório, descritivo, de campo e com abordagem quantitativa, realizado em uma maternidade de Salvador. Resultados: Foram analisados 62 registros, sendo a mediana da idade materna 25 anos. (46,8\%) se declaravam pretas, (50\%) em união estável, $(40,3 \%)$ possuíam o ensino médio completo e $(58,1 \%)$ estavam desempregadas. Das características obstétricas $(98,4 \%)$ realizaram o pré-natal, $(46,8 \%)$ receberam orientações sobre amamentação durante as consultas, (13,1\%) apresentaram sífilis durante a gestação e $(69,4 \%)$ tiveram parto vaginal. Das características reprodutivas $(50 \%)$ iniciaram a vida sexual com idade de 13 a 15 anos, (35,3\%) faziam uso de pílula combinada antes da gestação e $(51,6 \%)$ eram primíparas. Conclusão: Os dados do presente estudo possibilitaram uma maior compreensão da ocorrência de intercorrências mamárias, bem como o perfil socioeconômico, reprodutivo e obstétrico de lactantes, que contribui para a promoção de ações e estratégias para prevenir essas ocorrências.
\end{abstract}

Palavras-chave: Doenças mamárias, Aleitamento materno, Período pós-parto.

\begin{abstract}
Objective: To describe the sociodemographic profile, reproductive and obstetric of women with breast disorders associated to breastfeeding in a maternity hospital in Salvador-Bahia (BA). Methods: Exploratory study, descriptive, of field study with a quantitative approach, accomplished in a maternity hospital in Salvador. Results: A total of 62 records were analyzed, and the median age being 25 years. $(46.8 \%)$ declared themselves black, $(50 \%)$ in a stable union, $(40.3 \%)$ had completed high school and $(58.1 \%)$ were unemployed. Of the obstetric characteristics $(98.4 \%)$ performed prenatal, $(46.8 \%)$ received guidance on breastfeeding during consultations, (13.1\%) had syphilis during pregnancy and $(69.4 \%)$ had vaginal delivery of the reproductive traits $(50 \%)$ they started their sexual life with 13 to 15 years of age, (35.3\%) used a combination pill before gestation and (51.6\%) were primiparous. Conclusion: Data from recent study made possible a greater understanding of the occurrence of breast complications, as well as the socioeconomic, reproductive and obstetric profile of infants, which contributes to the promotion of actions and strategies to prevent those occurrences.
\end{abstract}

Key words: Breast diseases, Breast feeding, Postpartum period.

${ }^{1}$ Escola Bahiana de Medicina e Saúde Pública (EBMSP), Salvador - BA. *E-mail: flavinha-vaz@hotmail.com

2 Universidade Salvador (UNIFACS), Salvador - BA.

${ }^{3}$ Centro Universitário Jorge Amado (UNIJORGE), Salvador - BA

SUBMETIDO EM: 10/2019

ACEITO EM: 11/2019

PUBLICADO EM: 2/2020 


\section{RESUMEN}

Objetivo: Describir el perfil sociodemográfico, reproductivo y obstétrico de las mujeres con complicaciones mamarias relacionadas con la lactancia materna en una maternidad de Salvador-Bahía. Métodos: Estudio exploratorio, descriptivo, de campo y con abordaje cuantitativo, realizado en una maternidad de Salvador (BA). Resultados: Se analizaron 62 registros, con la mediana de la edad materna a los 25 años. (46,8\%) se declaraban negras, $(50 \%)$ en unión estable, $(40,3 \%)$ poseían la enseñanza media completa y $(58,1 \%)$ estaban desempleadas. En la mayoría de los casos, se observó un aumento de la mortalidad por rotavirus en los últimos años. De las características reproductivas (50\%) iniciaron la vida sexual con edad desde los 13 hasta los 15 años, $(35,3 \%)$ hacían uso de la píldora combinada antes de la gestación y $(51,6 \%)$ eran primíparas. Conclusión: Los datos del presente estudio han posibilitado una mayor comprensión de la ocurrencia de complicaciones mamarias, así como el perfil socioeconómico, reproductivo y obstétrico de las lactantes, que contribuye a la promoción de acciones y estrategias para prevenir esas ocurrencias.

Palabras clave: Enfermedades de la mama, Lactancia Materna, Periodo Posparto.

\section{INTRODUÇÃO}

A Organização Mundial da Saúde (OMS) preconiza que o aleitamento materno exclusivo (AME) seja mantido até os seis meses de idade, e de forma complementar até os dois anos de vida da criança. Essa recomendação baseia-se na variedade de benefícios provenientes da prática, a exemplo da prevenção contra doenças, auxílio da regressão uterina, formação de vínculo, bem como a redução da incidência de câncer de ovário e de mama (UNICEF, 2012). Soma-se ainda o favorecimento do desenvolvimento facial, oral, dentário, respiratório e cognitivo, além de ser uma opção de baixo custo (BRASIL, 2015).

Apesar dos benefícios já conhecidos, uma pesquisa realizada pela OMS e pelo Fundo das Nações Unidas para a Infância (UNICEF) mostra que apenas $51 \%$ dos bebês de 0 a 30 dias são amamentados exclusivamente, caracterizando o que se denomina desmame precoce (OLIVEIRA AK, et al., 2017).

Diversos fatores contribuem para o desmame precoce. Os motivos para a baixa aderência à prática estão relacionados a fatores sociais, como baixa renda, escolaridade e trabalho materno, bem como a ocorrência de complicações mamárias (MACHADO M, et al, 2014; ALVARENGA SC, et al., 2017). Estas podem favorecer a introdução precoce de alimentos e líquidos na nutrição do lactente, diminuindo a duração do aleitamento materno e aumentando os riscos de contaminação, reações alérgicas e os índices de morbimortalidade infantil (MARTINS C, et al., 2014).

Durante a amamentação, as puérperas podem enfrentar algumas complicações para amamentar, como ingurgitamento mamário, baixa ou alta produção de leite, traumas mamilares, mastite, candidíase, galactocele e abcessos mamários, bem como a má pega e o esvaziamento inadequado da mama. Diante deste fato, percebemos a importância em conhecer qual o perfil das mulheres que apresentam tais complicações para manejo adequado, visto que sua ocorrência pode prejudicar na manutenção do aleitamento materno (ALVARENGA SC, 2017).

Este estudo tem como objetivo descrever o perfil sociodemográfico, reprodutivo e obstétrico das mulheres com intercorrências mamárias relacionadas à amamentação em uma maternidade de Salvador-Bahia (BA).

\section{MÉTODOS}

Foi realizado um estudo exploratório descritivo, de campo e com abordagem quantitativa, que buscou descrever o perfil sociodemográfico, reprodutivo e obstétrico das mulheres com intercorrências mamárias relacionadas à amamentação em uma maternidade de Salvador - BA. Diante das justificativas expostas, questiona-se: Qual o perfil sociodemográfico e reprodutivo de mulheres com intercorrências relacionadas à amamentação em uma maternidade Amiga da Criança? A maternidade na qual foi realizado o estudo possui o título de Hospital Amigo da Criança, iniciativa idealizada pela OMS e pela UNICEF, com o objetivo de 
promover o aleitamento materno a partir da conscientização dos seus profissionais sobre sua importância para o bebê e para mãe.

Os dados foram coletados através da aplicação de um formulário de pesquisa contendo 29 perguntas relativas ao histórico reprodutivo e obstétrico, além de dados sociodemográfico no segundo dia de internação, momento em que com mais frequência ocorrem as intercorrências mamárias, com o objetivo de conhecer o perfil das mulheres que apresentam intercorrências mamárias.

Em relação às perguntas do questionário do presente estudo, foram traçadas perguntas direcionadas ao perfil sociodemográfico. São elas: estado civil; procedência; cor; escolaridade; renda familiar; profissão; ocupação; vínculo profissional.

Além disso, foi realizado o perfil reprodutivo (idade da primeira relação sexual; número de parceiros sexuais; se teve infecção sexualmente transmissível; número de gestações; intervalo interpartal menor que dois anos); e perfil obstétrico (realizou pré-natal; número de consultas pré-natal; problemas de saúde identificados no pré-natal; intercorrências gestacionais; se recebeu orientação sobre amamentação no prénatal e qual profissional que orientou; tipo de parto; complicações no parto; presença de acompanhante durante o parto; complicações pós-parto; peso do bebê ao nascer).

O formulário foi aplicado por duas alunas do curso de enfermagem devidamente capacitadas pelo curso de manejo da lactação, oferecido pela própria maternidade e treinadas para identificação dessas complicações e se necessário posterior manejo.

Foi feito o convite às pacientes, apresentados os objetivos, benefícios e riscos do estudo, e posteriormente assinatura do Termo de Consentimento Livre e Esclarecido (TCLE). As pacientes foram examinadas em local reservado, promovendo toda privacidade à mesma. Cada entrevista teve máximo de 10 minutos cada.

A amostra foi constituída por puérperas, que estiverem na referida unidade no período delimitado para coleta de dados. Como critérios de inclusão: puérperas com 18 anos ou mais, que estejam no alojamento conjunto, no segundo dia de hospitalização e internadas ou acompanhando seus recém-nascidos no alojamento conjunto e que tenham apresentado intercorrências mamárias (abscesso mamário, candidíase, galactocele, ingurgitamento mamário, mastite e trauma mamilar). Como critérios de exclusão: mulheres que não pariram na maternidade e estão internadas por outros motivos que não o parto, ou com alguma deficiência auditiva e/ou cognitiva, que inviabilize a aplicação do instrumento.

Para calcularmos o n amostral, realizou-se o cálculo na calculadora Winpepi®. Consideramos o estudo de Castro KF (2009), que apresenta uma proporção de intercorrências mamárias de $82,1 \%$. Desta forma assumimos uma proporção de $82 \%$, com um intervalo de confiança de $95 \%$, e uma diferença aceitável de 10\%, sendo necessário dessa forma 57 pacientes.

Os dados foram analisados por meio do programa Statistical Package for Social Sciences $\AA_{(S P S S)}$ versão 14 para Windows. As variáveis numéricas que apresentarem distribuição normal serão apresentadas em média $(\mathrm{m})$ e desvio padrão (DP); e as com distribuição assimétrica serão apresentadas em mediana (M) e intervalo interquartil (IQ). Já as variáveis categóricas serão apresentadas através da distribuição de frequências das categorias (representadas em percentual).

As informações da referida pesquisa foram utilizadas para fins exclusivamente científicos, obedecendo a Resolução no 466, de dezembro de 2012, do Conselho Nacional de Saúde, a qual aprova diretrizes e normas regulamentadoras de pesquisas envolvendo seres humanos. As despesas totais da pesquisa foram custeadas pela pesquisadora responsável, não havendo ônus para os participantes e demais envolvidos. A pesquisa foi aprovada pelo Comitê de Ética em Pesquisa (CEP) tendo 2.614.738 como número do parecer.

\section{RESULTADOS}

Foram convidadas 65 puérperas para participar do estudo, entretanto 62 aceitaram o convite. Com base na análise dos resultados, constatou-se que $1(1,6 \%)$ das mulheres teve abscesso mamário, $25(40,3 \%)$ ingurgitamento mamário e $39(62,9 \%)$ trauma mamilar. As demais intercorrências incluídas no trabalham 
como: candidíase, galactocele e mastite, não apresentaram frequência. A partir dos 62 registros analisados, identificou-se que a idade materna variou entre 18 e 36 anos, com mediana de 25 anos, se declaravam pretas $(46,8 \%)$, em união estável $(50 \%)$, tinham ensino médio completo $(40,3 \%)$ e eram procedentes de Salvador $(91,9 \%)$, conforme demonstra a (Tabela 1).

Tabela 1 - Características sociodemográficas de puérperas de um Hospital Amigo da Criança, $n=62$. Salvador - BA, 2018.

\begin{tabular}{|c|c|c|}
\hline Variável & $\mathbf{N}$ & $\%$ \\
\hline \multicolumn{3}{|l|}{ Estado civil } \\
\hline Solteira & 19 & 30,6 \\
\hline Casada & 11 & 17,7 \\
\hline Divorciada & 0 & 0 \\
\hline Viúva & 1 & 1,6 \\
\hline União Estável & 31 & 50 \\
\hline \multicolumn{3}{|l|}{ Procedência } \\
\hline Salvador & 57 & 91,9 \\
\hline Região Metropolitana & 1 & 1,6 \\
\hline Interior & 4 & 6,5 \\
\hline Outro estado & 0 & 0 \\
\hline \multicolumn{3}{|l|}{ Cor } \\
\hline Branca & 6 & 9,7 \\
\hline Preta & 29 & 46,8 \\
\hline Parda & 27 & 43,5 \\
\hline Outro & 0 & 0 \\
\hline \multicolumn{3}{|l|}{ Escolaridade } \\
\hline Analfabeta & 0 & 0 \\
\hline Ensino fundamental completo & 8 & 12,9 \\
\hline Ensino fundamental incompleto & 9 & 14,5 \\
\hline Ensino médio completo & 18 & 29 \\
\hline Ensino médio incompleto & 25 & 40,3 \\
\hline Ensino Superior & 2 & 3,2 \\
\hline Total & 62 & 100 \\
\hline
\end{tabular}

Fonte: Abreu AFV, et al., 2018.

A maioria das nutrizes $(46,8 \%)$ possuía renda familiar maior que um salário mínimo, sendo que grande parte $(53,2 \%)$ não tinha profissão, ocupação $(61,3 \%)$ e nem vínculo empregatício $(58,1 \%)$ (Tabela 2$)$. 
Tabela 2 - Perfil socioeconômico de nutrizes de uma maternidade Amiga da Criança, $n=62$. Salvador - BA, 2018.

\begin{tabular}{|c|c|c|}
\hline Variável & $\mathbf{N}$ & $\%$ \\
\hline \multicolumn{3}{|l|}{ Renda familiar } \\
\hline Sem renda & 1 & 8,1 \\
\hline < um salário mínimo & 7 & 11,3 \\
\hline Um salário mínimo & 21 & 33,9 \\
\hline < 1 salário mínimo & 29 & 46,8 \\
\hline \multicolumn{3}{|l|}{ Profissão } \\
\hline Sem profissão & 33 & 53,2 \\
\hline Profissão de nível fundamental & 21 & 33,9 \\
\hline Profissão de nível médio & 7 & 11,3 \\
\hline Profissão de nível superior & 1 & 1,6 \\
\hline \multicolumn{3}{|l|}{ Ocupação } \\
\hline Sem ocupação & 38 & 61,3 \\
\hline Ocupação de nível fundamental & 18 & 29 \\
\hline Ocupação de nível médio & 5 & 8,1 \\
\hline Ocupação de nível superior & 1 & 1,6 \\
\hline \multicolumn{3}{|l|}{ Vínculo profissional } \\
\hline Carteira assinada & 13 & 21 \\
\hline Profissional liberal & 0 & 0 \\
\hline Desempregada & 36 & 58,1 \\
\hline Autônoma & 12 & 19,4 \\
\hline Outro & 1 & 1,6 \\
\hline Total & 62 & 100 \\
\hline
\end{tabular}

Fonte: Abreu AFV, et al., 2018.

A Tabela 3 demonstra o resultado do perfil reprodutivo das lactantes. Metade das mulheres (50\%) referiram que iniciaram a vida sexual com idade entre 13 e 15 anos e tiveram entre tiveram 2 e 5 parceiros sexuais $(67,7 \%)$. No que se refere às infecções sexualmente transmissíveis, $82,3 \%$ das mulheres apresentaram resultado negativos. O método contraceptivo mais utilizado referido pelas mulheres foi a pílula combinada $(35,5 \%)$ e tiveram em sua maioria 1 gestação $(51,6 \%)$. No que concerne ao intervalo interpartal, $85,5 \%$ tiveram um intervalo maior que dois anos, e $80,6 \%$ das puérperas já sofreram aborto, conforme demonstrado na Tabela 3. 
Tabela 3 - Perfil reprodutivo de puérperas de um Hospital Amigo da Criança, n=62. Salvador - BA, 2018.

\begin{tabular}{lll}
\hline Variável & $\mathbf{N}$ & $\%$ \\
\hline Idade da primeira relação sexual & 2 & 3,2 \\
\hline $10-12$ & 31 & 50 \\
$13-15$ & 26 & 41,9 \\
$16-18$ & 1 & 1,6 \\
$19-21$ & 2 & 3,2 \\
$\geq 22$ anos & & \\
\hline No de parceiros sexuais & 2 & 3,2 \\
1 & 42 & 67,7 \\
$2-5$ & 15 & 24,2 \\
$6-10$ & 3 & 4,8 \\
$>10$ & &
\end{tabular}

\begin{tabular}{lll}
\hline $\begin{array}{l}\text { Teve alguma infecção sexualmente } \\
\text { transmissível }\end{array}$ & \\
\hline Sim & 11 & 17,7 \\
Não & 51 & 82,3 \\
\hline № gestações & 32 & 51,6 \\
\hline Uma & 18 & 29 \\
Duas & 6 & 9,7 \\
Três & 6 & 9,7 \\
Outro & 8 & 27 \\
\hline Intervalo interpartal menor que dois anos & 22 & 73 \\
\hline Sim & 62 & 100 \\
\hline Não & 82 & \\
\hline Total & & \\
\hline
\end{tabular}

Fonte: Abreu AFV, et al., 2018.

Quanto ao perfil clínico e obstétrico, a maioria das mulheres realizou pré-natal (98,4\%), sendo que 49,2\% das mulheres realizaram de 4 a 7 consultas. Entre as puérperas entrevistadas, $87,1 \%$ relataram não terem tido intercorrências gestacionais, entretanto o problema de saúde mais identificado no pré-natal foi a sífilis $(13,1 \%)$. Com relação à orientação sobre amamentação no pré-natal, $53,2 \%$ das mulheres referiam não ter recebido nenhum tipo de informação a respeito do tema, sendo o médico o sujeito que mais foi relatado como orientador da prática $(58,6 \%)$ (Tabela 4$)$. 
Tabela 4 - Perfil clínico e gestacional de puérperas de um Hospital Amigo da Criança, $n=62$. Salvador - BA, 2018.

\begin{tabular}{lll}
\hline Variável & N & $\%$ \\
\hline Realizou pré-natal & & \\
\hline Sim & 61 & 98,4 \\
Não & 1 & 1,6 \\
\hline No de consultas pré-natal & & \\
\hline $1-3$ & 8 & 13,1 \\
$4-7$ & 30 & 49,2 \\
$\geq 8$ consultas & 22 & 36,1 \\
\hline
\end{tabular}

\begin{tabular}{lll}
\hline $\begin{array}{l}\text { Problemas de saúde identificados no pré- } \\
\text { natal }\end{array}$ & 5 & \\
\hline Hipertensão & 0 & 8,2 \\
Diabetes & 4 & 0 \\
Anemia & 0 & 6,6 \\
Zika & 0 & 0 \\
Dengue & 8 & 0 \\
Sífilis & 4 & 13,1 \\
Outro & & 6,6 \\
\hline Intercorrências gestacionais & \\
\hline Hemorragia & 0 & 0 \\
Sangramento & 5 & 8,1 \\
Ameaça de aborto & 3 & 4,8 \\
Nenhum & 54 & 87,1 \\
\hline Recebeu orientações sobre amamentação & & \\
no pré-natal & 29 & 46,8 \\
\hline Sim & 33 & 53,2 \\
Não & & \\
\hline
\end{tabular}

\section{Profissional que orientou*}

\begin{tabular}{lll}
\hline Enfermeiro & 12 & 41,4 \\
Técnico de enfermagem & 0 & 0 \\
Médico & 17 & 58,6 \\
Nutricionista & 0 & 0 \\
Outro & 0 & 0 \\
\hline Total & $\mathbf{6 2}$ & $\mathbf{1 0 0}$ \\
\hline
\end{tabular}

Fonte: Abreu AFV, et al., 2018.

${ }^{*}$ Foram aceitas mais de uma resposta 
No que se refere às características do parto, nascimento e puerpério, o tipo de parto mais relatado foi o vaginal $(69,4 \%), 85,5 \%$ das mulheres relataram não terem tido complicações no parto e $62,9 \%$ referiram presença de acompanhante na sala de parto. Quanto às complicações pós-parto, 95,2\% relataram não ter tido nenhuma complicação e 37,1\% das mulheres informaram que seus bebês tiveram $<3,5 \mathrm{~kg}$ ao nascer (Tabela 5).

Tabela 5 - Características do parto, nascimento e puerpério de mulheres de uma Maternidade Amiga da Criança, $n=62$. Salvador - BA, 2018.

\begin{tabular}{|c|c|c|}
\hline Variável & $\mathbf{N}$ & $\%$ \\
\hline \multicolumn{3}{|c|}{ Tipo de parto } \\
\hline Vaginal & 43 & 69,4 \\
\hline Cesáreo & 19 & 30,6 \\
\hline Fórceps & 0 & 0 \\
\hline \multicolumn{3}{|c|}{ Complicações no parto } \\
\hline Sim & 9 & 14,5 \\
\hline Não & 53 & 85,5 \\
\hline \multicolumn{3}{|c|}{ Presença de acompanhante durante o parto } \\
\hline Sim & 39 & 62,9 \\
\hline Não & 23 & 37,1 \\
\hline \multicolumn{3}{|c|}{ Complicações pós-parto } \\
\hline $\operatorname{Sim}$ & 3 & 4,8 \\
\hline Não & 59 & 95,2 \\
\hline \multicolumn{3}{|c|}{ Peso do bebê ao nascer } \\
\hline$<2,5 \mathrm{~kg}$ & 7 & 11,3 \\
\hline$>2,5 \mathrm{~kg}$ & 13 & 21 \\
\hline$<3,5 \mathrm{~kg}$ & 23 & 37,1 \\
\hline$>3,5 \mathrm{~kg}$ & 18 & 29 \\
\hline$\geq 3,5 \mathrm{~kg}$ & 1 & 1,6 \\
\hline Total & 62 & 100 \\
\hline
\end{tabular}

Fonte: Abreu AFV, et al., 2018.

\section{DISCUSSÃO}

O presente estudo apresentou que a mediana da idade das puérperas entrevistadas foi de 25 anos. A idade materna é apresentada em alguns estudos como uma importante variável de interferência no estabelecimento do aleitamento materno (TORQUATO RC, 2018). Estes referem que nutrizes mais jovens 
têm menos dificuldades em amamentar, em virtude do acesso às informações relacionadas aos benefícios e vantagens sobre a prática da amamentação. Todavia, no estudo de DIAS, 2017, foi demonstrado que a idade materna não é um fator determinante para intercorrências mamárias. Dessa forma acredita-se que as participantes do presente estudo apresentaram intercorrências mamárias devido à inexperiência e insegurança com a amamentação, já que a maioria era primípara.

Ao analisarmos a situação conjugal, observou-se que a união estável foi a mais relatada pelas mulheres. Esse resultado diverge do estudo de Viduedo AFS, (2015), em que predomina a frequência de intercorrências mamárias em mulheres solteiras. Para esse autor, a presença do parceiro é fundamental para a redução do estresse causado pela amamentação e manutenção do aleitamento materno, visto que o cônjuge é uma figura forte que compõem a rede social de apoio da nutriz, de modo que a situação conjugal traz melhorias quanto à situação psicológica e financeira, inclusive na divisão de tarefas domésticas.

Apesar da divergência do resultado, presume-se que a situação conjugal das mulheres não representa qual a participação do conjugue para apoio ao aleitamento materno, bem como para prevenção e identificação precoce da intercorrência mamária, visto que nem sempre é o conjugue que estará presente durante a internação da paciente no alojamento conjunto, cenário da presente pesquisa.

Ao serem questionadas sobre a procedência, 91,9\% das mulheres referiam serem de Salvador. Acreditase que por ser um instituto de referência na capital, as mulheres são encaminhadas para lá, tendo dessa forma, poucos atendimentos referenciados por outros municípios ou capitais.

No quesito cor da pele, observou-se que a maioria das mulheres que tinham intercorrências mamárias se declarava preta, aspecto que diverge de alguns estudos (DIAS JS, 2017; COCA KP, 2009). O estudo de Dias, 2017, mostrou que mulheres de cor preta são menos propensas a apresentar traumas mamilares, devido à maior quantidade de melanina na aréola, característica que aumenta a resistência da pele. Entretanto há estudos que não relacionam a ocorrência de complicações mamárias com a cor da pele (COCA KP, 2008). Dessa forma acredita-se que a predominância de mulheres dessa cor com intercorrências mamárias, pode estar relacionada por Salvador ser uma capital que há uma elevada concentração de indivíduos da cor preta, compreendendo sua ocorrência.

A escolaridade das puérperas apresentou em maior número a completude do ensino médio completo, achado que converge com a literatura, em que a maioria das puérperas possuía segundo grau completo (VIDUEDO AFS, 2015; AMARO FG, 2016). Um estudo realizado em Ribeirão Preto (São Paulo) demonstra que mulheres com maior nível de escolaridade estão igualmente expostas às intercorrências mamárias, quando comparadas com mulheres de baixa escolaridade (VIDUEDO AFS, 2015). Tais intercorrências podem estar relacionadas a outras causas, a exemplo da anatomia mamária, pigmentação e formato do mamilo de cada mulher.

Ao analisar a renda, estudo demonstrou que as nutrizes possuíam renda familiar acima de 1 salário mínimo. A maternidade está localizada no distrito sanitário de Brotas, bairro que comporta uma população de baixa renda (SALVADOR, 2016). De acordo com o estudo de Barbieri MC (2015), mulheres de baixa renda realizam menos consultas de pré-natal ou as realizam tardiamente. Acredita-se que o pré-natal é um veículo de informação para a mulher, em que dúvidas serão reduzidas e as mesmas orientadas quanto à amamentação, bem como as possíveis intercorrência envolvidas. Dessa maneira, presume-se que as puérperas tiveram o preparo e orientação inadequada das mamas no período gestacional e puerperal, favorecendo o aparecimento das intercorrências mamárias.

Foi relatado que a maioria das puérperas não tinha profissão, ocupação e nem vínculo profissional. De acordo com os resultados obtidos na pesquisa, grande parte das lactentes informou estar desempregadas. Dos estudos que tivemos acesso, não foram encontradas pesquisas que relacionassem o vínculo profissional com o aparecimento das intercorrências mamárias, porém, supõe-se que as nutrizes tenham estabelecido um horário fixo para amamentar, interrompendo a amamentação em livre demanda, e não tenham tido orientações sobre ordenha e nem avaliação das mamas por meio dos profissionais do pré-natal e talvez da maternidade. Teoricamente, em virtude da disponibilidade de tempo e da consequência ausência de atividade 
laboral, essas mulheres poderiam ter acesso a informação relacionada a prática, entretanto o que se apresenta é totalmente o inverso.

Metade das mulheres teve a idade de iniciação sexual entre 13 e 15 anos. Estudos mostram que mulheres que iniciaram a vida sexual cedo têm mais riscos de gravidez indesejada (ZIMMERMMANN JB, 2011). Pressupõe-se que a ocorrência das intercorrências mamárias pode ter relação com a gravidez indesejada, visto que mães que não planejam uma gravidez podem rejeitar seus filhos, influenciando na vontade de amamentar, de aprender a técnica correta de amamentação, bem como na adesão ao pré-natal, não tendo orientações sobre as intercorrências no pré-natal.

De acordo com os resultados obtidos na pesquisa, quarenta e duas mulheres relataram ter de 2 a 5 parceiros sexuais. Até o momento, não foram encontrados estudos que relacionassem a quantidade de parceiros sexuais com o objetivo da pesquisa. Porém, acredita-se que mulheres que tiveram um elevado número de parceiros sexuais têm baixa adesão ao pré-natal, pois a falta de um parceiro fixo influencia no apoio à realização do mesmo, e isso acarreta no desconhecimento sobre aleitamento materno, técnicas de amamentação e pega correta.

Quanto às infecções sexualmente transmissíveis (IST's), 82,3\% não tiveram alguma. Esse achado vai de encontro com a literatura, pois mulheres que apresentavam IST's não amamentaram na primeira hora de vida, e isto pode influenciar no surgimento ou não de complicações mamárias, pois a mãe adquire autoconfiança em seu potencial para amamentar o lactente (BELO MNM, 2014; HERGESSELL NM, 2017). Acredita-se que a sucção precoce pode reduzir a incidência de ingurgitamento mamário e fissuras mamilares. Dessa forma, considera-se que o aparecimento das intercorrências mamárias esteja atrelado à primiparidade, dificuldade na pega, mamilos curtos/planos ou invertidos e esvaziamento inadequado da mama.

Foi observado que a grande parte das mulheres entrevistadas era primípara. Um estudo realizado nos Estados Unidos observou que a primiparidade relacionou-se com a presença de intercorrências mamárias em decorrência da inexperiência da nutriz (DIAS JS, 2017; COCA KP, 2009; CERVELLINI MP, 2014). Sabe-se que a falta de conhecimento a respeito da técnica de amamentação, a falta de habilidade e a ansiedade podem interferir no processo lactacional e gerar tais complicações. Isso intensifica mais quando as nutrizes não receberam orientações e nem supriram suas dúvidas sobre amamentação durante o pré-natal, enfatizando a importância do profissional de saúde na formação do vínculo mãe-bebê.

De acordo com os resultados, $73 \%$ das mulheres tiveram um intervalo interpartal maior que dois anos. Um intervalo menor que dois anos entre o parto é um fator de risco para a gravidez atual, sendo uma causa de morbidade materno-infantil podendo causar intercorrências gestacionais, como a placenta prévia e acretismo placentário (ANDRADE RD, 2015; SANTANA DSN, 2010). Dessa forma, o cuidado da equipe vai estar voltado para a puérpera, deixando as mamas para segundo plano, potencializando a ocorrência da complicação mamária. Acredita-se que o surgimento das intercorrências mamárias esteja associado com a não observação criteriosa da mamada pelos profissionais da maternidade, a não correção da pega e posição, além da ausência de instrução durante o pré-natal.

Conforme os resultados analisados, das sessenta e duas mulheres apenas uma não realizou o prénatal. O estudo de Skupien SV, (2016), também mostra a adesão positiva para o pré-natal, entretanto teoricamente tinham que ter menos complicações mamárias (SKUPIEN SV, 2016). Acredita-se que as nutrizes que tiveram intercorrências mamárias e que realizaram o pré-natal não participaram de ações educativas (como grupos de gestantes), não tiveram o preparo das mamas ou nem foram orientadas corretamente durante as consultas de pré-natal. Destaca-se ainda a condução para identificação precoce e manejo adequado das intercorrências no alojamento conjunto, local em que a maioria delas são estabelecidas.

De acordo com os resultados, a maioria compareceu entre quatro a sete consultas, assim como o estudo de Barbosa EM, (2017), em que as lactantes realizaram mais de seis consultas. Considera-se que as mulheres apresentaram complicações mamárias devido à falta de orientação sobre amamentação. Sabe-se que o prénatal é importante para promover um bom desenvolvimento gestacional, para detectar alterações fetais e 
fornecer orientações e conhecimento sobre amamentação. Para alcançar esse objetivo, o Ministério da Saúde preconiza que o número de consultas deve ser no mínimo 6 (seis) (BRASIL, 2015). O principal problema de saúde na gestação relatado foi a sífilis $(13,1 \%)$.

De acordo com o estudo Sonda EC, (2013), a sífilis pode ser transmitida para o bebê por meio do canal de parto (parto vaginal) caso haja lesões genitais. Dessa maneira, muitas vezes é recomendado o parto cesáreo. Este tipo de parto está relacionado com o surgimento de intercorrências mamárias (AMARO FG, 2016). Também, a transmissão da sífilis pode-se dar pelo aleitamento materno desde que lesões mamárias estejam presentes (SONDA EC, 2013). Acredita-se que a relação entre esta patologia com o surgimento de complicações mamárias deve-se ao tipo de parto, que favorece o surgimento dessas intercorrências, e consequentemente a sua interrupção, pois é contraindicada a amamentação com a presença de fissuras mamárias.

Segundo o estudo, cinquenta e quatro mulheres não apresentaram intercorrências gestacionais. Porém, estudos comprovam que hemorragia, sangramento e ameaça de aborto podem influenciar em nascimento de bebês prematuro (ALVES JAG, 2010). Recém-nascidos pré-termo (RNPT) podem ter o reflexo de sucção ineficaz devido ao longo período de internação, quebra do vínculo com a mãe e a não amamentação na primeira hora de vida (GOMES ALM, 2017).

Dessa maneira, a prematuridade interfere no processo lactacional, causando alterações mamárias. Contudo, como no presente estudo houve poucos casos de complicações gestacionais, acredita-se que as intercorrências mamárias estão associadas com disfunções orais no bebê, não esvaziamento completo das mamas e produção excessiva ou deficiente de leite materno, indicando a ocorrência das complicações.

Apesar de terem realizado uma boa quantidade de consultas do pré-natal, apenas $53,2 \%$ das mulheres tiveram orientações sobre aleitamento materno, aspecto que aumenta 0 risco de interrupção da amamentação, bem como o risco de desenvolver intercorrências mamárias. Esse resultado corrobora com a literatura (SKUPIEN SV, 2016; BATISTA KRA, 2013). O estudo de Ferreira, 2018, por exemplo, mostrou que metade das participantes do estudo dele não receberam orientações em educação em saúde a respeito da amamentação durante o pré-natal (FERREIRA HLO, 2018).

Dessa forma, com a falta de informação nas consultas, as mulheres podem buscar tais conhecimentos no senso comum e serem influenciadas pelas crenças, causando a interrupção do aleitamento materno, a falta de prevenção da intercorrência bem como da sua identificação e manejo precoce. No presente estudo, a maioria das lactantes receberam orientações acerca do aleitamento materno por intermédio dos profissionais de medicina. Talvez a paciente não conseguiu diferir os profissionais médicos e enfermeiros, visto que este 0 profissional que mais realiza ações de promoção da amamentação na atenção básica, bem como consultas de pré-natal (BARBIERI MC, 2015). Dessa forma acredita-se que o surgimento de intercorrências mamárias pode estar atrelado à falta de educação em saúde fornecida pela unidade de saúde onde a mulher realizou o pré-natal.

Por ser um instituto de referência da capital e por estimular a prática de partos vaginais, observou-se que a maioria das mulheres que tinha complicações mamárias pariram dessa forma, resultado que diverge da literatura (SANTOS KJS, 2016; PASUPATHY D, 2008). O estudo de Dias JS, (2017), relata que mães de parto cesáreo foram mais propensas às intercorrências mamárias em comparação com as mulheres que tiveram parto vaginal. Esse estudo argumenta que a dor causada pela incisão cirúrgica pode afetar no posicionamento correto da criança no seio materno, prejudicando a pega e colaborando para ocorrência de traumas mamilares e ingurgitamento mamário (DIAS JS, 2017). Dessa maneira, pressupõe-se que a ocorrência de intercorrências mamárias esteja ligada a diversos aspectos, como alterações mamilares, primiparidade, pega incorreta e condução deficitária durante a internação no alojamento conjunto.

Em relação às complicações durante o parto, $85,5 \%$ das nutrizes relataram não ter tido alguma. Dessa forma acredita-se que o episódio de intercorrências mamárias está concatenado com a não amamentação nas duas mamas, a falta de ordenha do leite retido e o não uso de sutiãs para proporcionar suspensão mamária e facilitar a descida do leite, condutas que devem ser tomadas durante o processo, no alojamento 
conjunto. Foi relatado presença de acompanhante na maioria dos partos. Não foram encontrados estudos que relacionassem a presença de acompanhante com o surgimento de intercorrências mamárias. Acreditase que as nutrizes tiveram acompanhantes durante o parto porque a referida maternidade onde ocorreu a pesquisa é certificada como Amiga da Criança, e prioriza a presença de acompanhante de livre de escolha para oferecer apoio durante o pré-parto, parto e pós-parto.

Quanto às complicações pós-parto 95,2\% não tiveram alguma. O estudo de Mascarello demonstra que as complicações mais frequentes são associadas ao parto cesáreo, são elas: infecção puerperal e complicações da ferida cirúrgica, e associada ao parto vaginal tem-se o trauma obstétrico, que inclui laceração do períneo e da vagina (MASCARELLO KC, 2017). A maioria das mulheres teve parto vaginal, e por ser uma maternidade credenciada como Amiga da Criança, acredita-se que não passaram por intervenções desnecessárias, como episiotomia.

Sabe-se que as complicações pós-parto podem interferir no processo lactacional, principalmente quando a mãe sente dores, favorecendo a técnica incorreta para amamentar. Porém, como grande parte não teve complicações pós-parto, presume-se que a incidência de intercorrências mamárias nessas mulheres deve-se ao fato da falta de assistência no alojamento conjunto, como intensificar as vantagens e benefícios do aleitamento materno e explicar o modo correto de amamentar.

Em relação ao peso do recém-nascido, a pesquisa constatou que a maioria tinha peso adequado para a idade gestacional (AIG). Não foram encontrados estudos que associassem bebês AIG com complicações mamárias. Porém, o estudo de Sassá AH, 2014, demonstra que bebês com baixo peso ao nascer têm mais dificuldade na pega, uma vez que o recém-nascido PIG (pequeno para a idade gestacional) tem a boca muito pequena, e não se adequa ao seio (SASSÁ AH, 2014). Dessa forma, acredita-se que a ocorrência da complicação esteja relacionada com a falta de técnica para amamentar, a má pega, esvaziamento incompleto da mama ou do posicionamento incorreto da criança ao seio.

\section{CONSIDERAÇÕES FINAIS}

Diante do exposto, conclui-se que as principais intercorrências mamárias foram ingurgitamento mamário, trauma mamilar e abscesso mamário, sendo mais predominante em puérperas em união estável, de cor preta, com ensino médio completo, desempregadas, primíparas, que realizaram o pré-natal, não tiveram orientação sobre amamentação e realizaram o parto por via vaginal. Mesmo tendo em vista que o estudo foi realizado numa maternidade Amiga da Criança, é possível perceber ainda a ocorrência de intercorrências mamárias. Ao analisar os artigos que foram utilizados para auxiliar na elaboração do presente estudo, percebemos um déficit de estudos que abordassem mulheres com complicações mamárias, aspecto que limita a presente pesquisa. Sugestionamos que sejam feitos estudos futuros, com outros desenhos metodológicos, a fim de conhecer o real perfil dessas mulheres, para que se identifiquem os mesmos e colabore para elaboração de estratégias de prevenção de intercorrências mamárias.

\section{AGRADECIMENTOS}

Agradecemos à orientadora Flávia Pimentel, orientadora do projeto Amigas D'Leite e do nosso trabalho de conclusão de curso, que nos confiou a realização deste projeto, orientando de forma clara e concisa e sempre ao dispor para nos fornecer quaisquer esclarecimentos. Agradecemos também à instituição onde realizamos o estudo, pela oportunidade de ter aberto suas portas para que nós pudéssemos executá-lo com qualidade. E por final, agradecemos às clientes da maternidade, que foram pacientes e complacentes para responder 0 questionário aplicado.

\section{REFERÊNCIAS}

1. ALVARENGA SC, et al. Fatores que influenciam o desmame precoce. Aquichán, 2017; 17(1): 93-1-3.

2. ALVES JAG, et al. Ameaça de aborto: conduta baseada em evidências. Femina, 2010; 38(2): 111-115. 
3. AMARO FG, et al. Fatores associados ao trauma mamilar na maternidade. J Pediatr, 2009; 85(4): 341-345.

4. ANDRADE RD, et al. Fatores relacionados à saúde da mulher no puerpério e repercussões na saúde da criança. Esc Anna Nery, 2015;19(1):181-186.

5. BARBIERI MC, et al. Aleitamento materno: orientações recebidas no pré-natal, parto e puerpério. Semina: Ciências Biológicas e da Saúde, 2015; 36(1):17-24.

6. BARBOSA EM, et al. Perfil sociodemográfico e obstétrico de parturientes de um hospital público. Rev Rene, 2017; $18(2): 227-233$.

7. BATISTA KRA, et al. Influência da assistência de enfermagem na prática da amamentação no puerpério imediato. Saúde em debate, 2013; 37(96):130-138.

8. BELO MNM, et al. Aleitamento materno na primeira hora de vida em um Hospital Amigo da Criança: prevalência, fatores associados e razões para sua não ocorrência. Rev Bras Saúde Matern Infant, 2014;14(1):65-72.

9. BRASIL. 2015. In: Saúde da criança: aleitamento materno e alimentação complementar. Brasília: Ministério da Saúde.

10. CASTRO KF, et al. Intercorrência mamárias relacionadas à lactação: estudo envolvendo puérperas de uma maternidade pública de João Pessoa, PB. O mundo da Saúde 2009, 33(4):433-9.

11. CERVELLINI MP, et al. Lesões mamilares decorrentes da amamentação: um novo olhar novo para um problema conhecido. Rev Esc Enferm USP, 2014; 48(2):346-56.

12. COCA KP, ABRÃO ACF. Avaliação do efeito da lanolina na cicatrização dos traumas mamilares. Acta Paul Enferm, 2008; 21(1):11-16.

13. COCA KP, et al. Fatores associados ao trauma mamilar na maternidade. J Pediatr, 2009; 85(4):341-345.

14. DIAS JS, et al. Fatores associados ao trauma mamilar no período de lactação: uma revisão sistemática. Rev Bras Saude Matern Infantil, 2017; 17(1):43-58.

15. FERREIRA HLO, et al. Fatores Associados à Adesão ao Aleitamento Materno Exclusivo. Ciênc saúde colet, 2018; 23(3):683-690.

16. GOMES ALM, et al. Aleitamento materno de prematuros em hospital amigo da criança: da alta hospitalar ao domicílio. Rev Rene, 2017;18(6):810-817.

17. HERGESSELL NM, LOHMANNLL PM. Aleitamento materno na primeira hora após o parto. Trabalho de Conclusão de Curso. Centro Universitário Univates, Lajeado, 2017.

18. MACHADO M, et al. Determinantes do abandono do aleitamento materno exclusivo: fatores psicossociais. Rev Saúde Pública, 2014; 48(6):986-94.

19. MARTINS C, et al. Introdução de alimentos para lactentes considerados de risco ao nascimento. Epidemiol Serv Saúde, 2014; 23(1):79-90.

20. MASCARELLO KC, et al. Complicações maternas e cesárea sem indicação: revisão sistemática e meta-análise. Rev Saude Publica, 2017; 51:105.

21. OLIVEIRA AK, et al. Práticas e crenças associadas ao desmame precoce. Av Enferm, 2017; 35(3):303-312.

22. PASUPATHY D, SMITH GCS. Resultados neonatais com parto cesáreo a termo. Arch Dis Child Fetal Neonatal, 2008; 93:174-175.

23. SALVADOR. 2016. In: Painel de informações: dados socieconômicos do município de Salvador por bairros e prefeituras-bairro. Conder/Informs.

24. SANTANA DSN, et al. Conceito, diagnóstico e tratamento de placenta prévia acreta com invasão de bexiga: revisão sistemática da literatura. Femina, 2010; 38(3):147-153.

25. SANTOS KJS, et al. Prevalência e fatores associados aos mamilos rachados no primeiro mês pós-parto. BMC Pregnancy and Childbirth, 2016;16:209.

26. SASSÁ AH, et al. Bebês pré-termo: aleitamento materno e evolução ponderal. Rev Bras Enferm, 2014; 67(4):594-600.

27. SKUPIEN SV, et al. Consulta puerperal de enfermagem: prevenção de complicações mamárias. Cogitare Enferm, 2016; $21(2): 01-06$.

28. SONDA EC, et al. Sífilis congênita: uma revisão da literatura. Rev Epidemiol Control Infect, 2013; 3(1):28-30.

29. TORQUATO RC, et al. Perfil de nutrizes e lactentes atendidos na Unidade de Atenção Primária de Saúde. Esc Anna Nery, 2018; 22(1): e20170212.

30. UNICEF. Manual de Aleitamento Materno. Portugal: Comité Português para UNICEF e Comissão Nacional Iniciativa Hospitais Amigos dos Bebés, 2012.

31. VIDUEDO AFS, et al. Mastite lactacional grave: particularidades da internação à alta. Rev Bras Enferm, 2015; 68(6):806-11.

32. ZIMMERMMANN JB, et al. Aspectos ginecológicos e obstétricos de pacientes atendidas nos serviços público e privado de saúde: há diferenças? Rev Bras Ginecol Obstet, 2011; 33(12):401-407. 